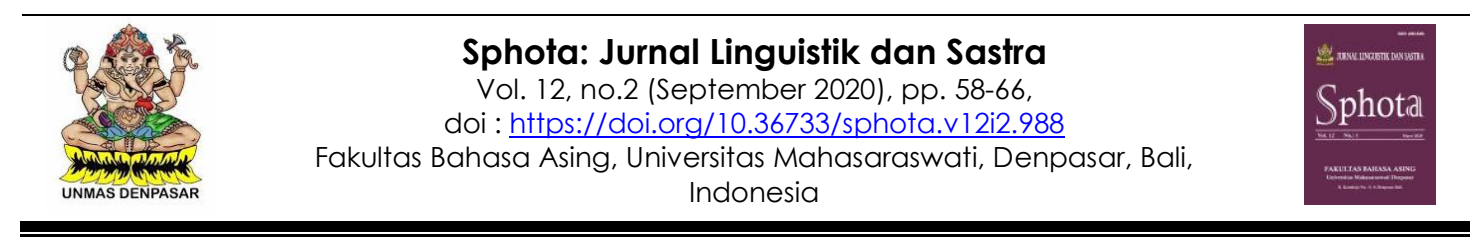

\title{
Tuhan Orang-Orang Kolok Desa Bengkala
}

\author{
Dian Rahmani Putri \\ Institut Teknologi dan Bisnis STIKOM Bali \\ dira.putri78@gmail.comrahmani@stikom-bali.ac.id
}

\begin{abstract}
The limit of ability in hearing and speaking in some people is not an obstacle to understanding the concept of God. This research aims at the discovering the range of understanding of the deaf community (Koloks) in Bengkala on the concept of God. Data sources are spoken texts, which were selected by using 'Go Fishing' technique, on which data have been collected randomly and without specific planning. The selected data were analysed by using the ethnographic method; their purpose is to collect several data that explain issues which are focusing on the conducted research. The result data are spoken texts; those are interviews with seven deaf people and three important persons in Bengkala village, namely Made Arpana (Former Head of the Village), Mangku Deni (temple priest), and Ketut Kanta, who is the Kelihan or the Chief of Bengkala Deaf Community. The result of this research comes to the conclusion that generally Bengkala deaf people know and understand the concept of God. Their spiritual life is vivid as they are following all the values and worship procedures according to Balinese-Hindu religion, which comprises daily worships, life-circle rituals, and religious ceremonies.
\end{abstract}

Keywords: Discourse Analysis, concept of God, Kata Kolok, Ethnography

\section{Pendahuluan}

Penelitian ini merupakan investigasi etnografi yang bertujuan untuk mengetahui apakah keterbatasan manusia menjadi halangan bagi manusia tersebut untuk menemukan dan memahami konsep Tuhan. Hal ini penting untuk diteliti menimbang dalam nilai-nilai kemanusiaan, secara umum Tuhan, yang adalah sumber segala yang ada dan sumber energi yang tertinggi yang mengatasi segala ciptaan, merupakan aspek terpenting untuk diyakini setiap manusia. Dengan adanya kekuatan yang mengatasi dirinya, manusia hidup dalam ketaatan kepada ajaran Tuhan sebagai sumber kebenaran dan menjalani kehidupan dengan melaksanakan perintahNya dan menjauhi laranganNya. Dengan berserahnya manusia kepada Kuasa yang lebih tinggi dari dirinya, yakni Tuhan, dengan melaksanakan agama, hal itu menjadi kekuatan dari dalam dirinya sendiri dalam menghadapi kehidupan. Mantra dan Agastia (1994) dalam makalahnya menyatakan bahwa agama adalah inner power atau tenaga dari dalam bagi pemeluknya dalam menghadapi berbagai tantangan hidup. Adalah penting untuk membangkitkan dinamisme dan vitalitas spiritual masyarakat dalam menghadapi dinamika kehidupan yang semakin kompleks di masa-masa mendatang sebab agama adalah faktor utama pewujudan berbagai pola persepsi dunia bagi manusia yang pada akhirnya juga mempengaruhi perkembangan dunia itu sendiri dan perjalanan sejarah manusia (2006:116).

Konsep tentang Tuhan menurut Socrates (469-399 SM), seorang filosof Yunani yang adalah murid Phytagoras, dengan pernyataannya yang terkenal, 'Gnoti Seauton' yang berarti kenalilah dirimu sendiri, dengan demikian dapat lebih mengenal Tuhan. Menurut Socrates, manusia diberikan sifat-sifat istimewa yang tidak dimiliki oleh 
ciptaan lainnya. Alam terjadi tidak secara kebetulan, semuanya terjadi menuju kepada satu tujuan yang bertingkat-tingkat ke tujuan yang lebih tinggi sehingga sampai ke tujuan yang absolut dan Esa. Menurut Socrates, ada dua jalan yang membangun pengetahuan manusia tentang Tuhan, pertama, berdasarkan kejadian alam dan kedua, dengan alasan sejarah yang menjabarkan karakter manusia yang sendirinya tertarik kepada eksistensi Tuhan yang menjadikan, mengatur dan memelihara manusia.

Pernyataan lainnya tentang Tuhan dari zaman yang berbeda sebagaimana disampaikan oleh Descartes (1596-1630 M). Descartes mengemukakan jalan pemikirannya untuk mengenal Tuhan. Pertama, di saat merasa diri berada dalam kekurangan, pada saat yang bersamaan juga merasa pastilah ada zat yang tidak kekurangan atau sempurna. Kedua, keberadaan tidak terjadi dengan sendirinya, sebab jika diri tersebut menjadikan dirinya sendiri, tentunya diri tersebut dapat memberikan kesempurnaan kepada dirinya sendiri. Ketiga, di dalam diri ada suatu perasaan terhadap adanya zat yang sempurna, sehingga Tuhan itu sudah jelas pasti ada. Kata 'Tuhan' menurut Descartes adalah ketuhanan yang tidak mempunyai kesudahan, yang asali, yang tak berawal dan tak berakhir, yang abadi, kekal, berdiri sendiri, yang mengetahui segala sesuatu dan yang merasa atas tiap-tiap sesuatu.

Wujud Tuhan tidak dapat dilihat oleh manusia secara nyata. Meskipun demikian, Tuhan memiliki makna dan arti yang sangat penting bagi sebagian besar umat manusia di seluruh belahan Bumi. Demikian halnya dengan orang-orang berkebutuhan khusus, dengan berbagai keterbatasan, mereka memahami tentang Tuhan sebagai pribadi yang absolut dan memiliki kuasa yang mahadahsyat yang dapat mereka alami dalam perjalanan hidup sehingga menjadi taat dan setia pada keyakinan mereka.

Demikian halnya dengan masyarakat kolok di Desa Bengkala. Berdasarkan data biro pusat statistik tahun 2014, tercatat dari 2819 warga Desa Bengkala termasuk di dalamnya 43 orang kolok (tuli-bisu) dari berbagai usia. Keadaan tuli-bisu ini dialami secara genetik. Ada penelitian di tahun 1995 yang menemukan bahwa kelainan pendengaran ini termasuk congenital deafness yakni kelainan fungsi pendengaran bawaan sejak lahir. Penelitian lainnya di tahun 1998 mengatakan bahwa kelainan pendengaran yang dialami para kolok di Desa Bengkala merupakan kelainan yang bersifat genetik, dengan rumus genetik DFNB3 yang memiliki kemiripan struktur dengan sebuah gen di India.

Berdasarkan observasi yang dilakukan secara langsung dan juga hasil wawancara dengan beberapa tokoh Desa Bengkala, warga kolok di Desa Bengkala diketahui memiliki sifat dasar yang aktif, rajin, berinisiatif dan memiliki ingatan yang kuat. Di lain pihak, warga Desa Bengkala yang mendengar (normal) memiliki karakter yang welas-asih, menyayangi saudara mereka yang kolok, melibatkan warga kolok dalam berbagai aktivitas desa dan memberdayakan orang-orang kolok. Hal ini tentu saja membangun kemandirian di antara warga desa yang mendengar maupun yang kolok. Tidak jarang mereka saling bahu-membahu dalam berbagai kegiatan, tanpa kecuali kegiatan keagamaan dan ekspresi mereka dalam meyakini dan menyatakan kehadiran Tuhan.

Meminjam pernyataan Creswell (2014), individu yang dipilih secara sengaja untuk studi yang diusulkan. Ide dibalik penelitian kualitatif adalah sengaja memilih peserta atau situs (atau dokumen atau materi visual) yang akan sangat membantu 
peneliti memahami masalah dan pertanyaan penelitian. Diskusi tentang peserta dan situs mungkin mencakup empat aspek seperti yang diidentifikasi oleh Miles dan Huberman (1994): (a) setting (yaitu, di mana penelitian akan dilakukan tempat), (b) aktor (yaitu, siapa yang akan diamati atau diwawancarai), (c) peristiwa (yaitu, apa akan diamati atau diwawancarai melakukan), dan (d) proses (yaitu, sifat peristiwa yang berkembang yang dilakukan oleh aktor di dalam latar). Pengamatan dilakukan bertahap untuk mencatat informasi sambil mengamati. Diperlukan catatan yang terpisah; catatan yang satu untuk mencatat berbagai rekonstruksi dialog, kisah peristiwa tertentu, deskripsi orang-orang, dan juga tentang aktivitas tertentu; dan catatan lainnya berisi pemikiran pribadi dari peneliti (Bogdan \& Biklen, 1992). Berdasarkan uraian berbagai teori para ahli di atas, dapat dirangkum dan dikembangkan ke dalam penelitian ini bahwa harapan penelitian untuk dapat mengetahui sejauh mana pemahaman orang tuli (Basa Bali: Kolok) di Desa Bengkala tentang konsep Tuhan dalam kehidupan mereka, yang oleh teori perencanaan penelitian seperti uraian di atas, kenyataan yang diperoleh dapat menjawab harapan peneliti bahwa orang Kolok juga memiliki pemahaman yang sama dengan orang dengan pendengaran yang wajar. Bahwa Tuhan dikenal baik oleh orang mendengar maupun orang tuli.

Penelitian ini ingin mengetahui lebih jauh bagaimanakah orang-orang tuli-bisu atau warga kolok di Desa Bengkala memahami tentang Tuhan dan bagaimanakah kehidupan rohani warga kolok Desa Bengkala ini? Apakah mereka mengalami sebuah pengalaman religius yang berbeda ataukah sama dengan orang-orang normal di sekitar mereka?

\section{Materi dan Metode}

Data merupakan teks lisan dalam bentuk rekaman video. Pengumpulan data dilakukan dengan teknik 'menangkap ikan' di mana data diperoleh dengan cara yang acak dan tanpa rencana khusus (Maisell dan Persell, 2009:80). Dalam hal ini peneliti melakukan perekaman bebas dengan introspeksi dan menunggu momen yang tepat, dengan pertimbangan bahwa yang direkam adalah kalangan difable (orang-orang yang memiliki kemampuan berbeda dari yang biasanya). Demikianlah data diambil dengan teknik pengajukan pertanyaan dan rekam dengan menggunakan handycam. Dalam proses wawancara tersebut, peneliti dibantu oleh seorang pembahan yang menerjemahkan isyarat yang disampaikan oleh warga kolok. Setelah rekaman video diperoleh, data rekaman disalin dalam bentuk tulisan dan diseleksi sesuai dengan kebutuhan yang digunakan untuk menjawab rumusan masalah. Selanjutnya data dianalisis dengan menggunakan metode etnografi, yakni membaca korpus data dan menghasilkan konsep yang berfungsi untuk memahami korpus data tersebut, seperti yang telah disampaikan oleh Hammersley dan Atkinson (1995:212).

\section{Hasil dan Pembahasan}

\section{Pemahaman Warga Kolok tentang Konsep Tuhan serta Peran Warga Kolok dalam Kegiatan Keagamaan dan Adat}

Warga kolok di Desa Bengkala diketahui memahami konsep tentang Tuhan. Mereka juga bersembahyang memohon kesehatan, keselamatan dan rezeki dari Tuhan dengan cara penyampaian mereka yang sederhana. Berikut ini rangkuman penjelasan 
Pak Kanta (65 tahun, Guru SD dan Petani, Sarjana Ekonomi, status: kawin) dari rekaman wawancara tersebut:

Dalam hal keagamaan, warga kolok di Desa Bengkala mengikuti peribadatan menurut agama Hindu Bali. Warga kolok juga biasa bersembahyang seperti orang normal. Saya sering bertanya kepada warga kolok apakah mereka bisa bersembahyang, jawaban mereka,meskipun mereka tidak bisa mengucapkan mantra, mereka bersembahyang dengan cara mereka sendiri, memohon kepada Tuhan (isyarat: menyembah dan menunjuk ke atas/ ke langit) agar sehat, bisa bekerja dengan baik, memperoleh rejeki dan permohonan lainnya. Warga kolok juga mengetahui sembahyang Purnama, Tilem, dan lain-lain, biasanya mereka bersembahyang di Pura Dadia dan Pura Kahyangan Tiga.

Mengikuti tradisi Desa Adat Bengkala, warga kolok juga mengenal upacara lingkar hidup seperti: mulai dari lahir ada upacara untuk bayi berumur 11 hari yakni di saat tali pusarnya terlepas (kepus puser), setelah itu upacara untuk bayi berumur 42 hari (abulan pitung dina) di mana sesaji dibuat untuk roh yang reinkarnasi pada bayi tersebut dan keluarga juga pergi menemui paranormal (balian) untuk menanyakan roh leluhur mana yang reinkarnasi pada bayi tersebut, selanjutnya ada upacara untuk bayi berumur tiga bulan (matelubulanan), lalu upacara untuk anak umur enam bulan (otonan). Yang unik di Bengkala, mereka tidak punya tradisi upacara menek kelih yakni untuk remaja akil-baliq.

Demikian pula upacara potong gigi (metatah) pada awalnya seluruh warga Desa Adat Bengkala belum mempunyai tradisi ini bahkan justru upacara potong gigi dilaksanakan saat seseorang meninggal dirangkaikan dengan upacara pengabenan-nya. Namun setelah tahun 80an, di mana upacara Ngaben massal telah ditetapkan dan diatur oleh pemerintah desa dilaksanakan 5 tahun sekali, barulah upacara potong gigi ini menjadi tradisi untuk pemuda/pemudi di Desa Bengkala yang dilaksanakan secara bersama-sama setelah upacara Ngaben massal. Hal ini dikarenakan keterbatasan biaya untuk dapat melaksanakan upacara potong gigi tersebut. Dalam pelaksanaan upacara keagamaan, warga kolok selalu dibantu oleh sanak-keluarganya.

Upacara keagamaan yang terkait dengan pertanian di Desa Bengkala, seluruh warga normal maupun kolok melaksanakan upacara mendak padi pada saat musim tanam, dan Soma Ribek di mana saat itu warga membuat jajan laklak. Terkait dengan laut, setiap dua tahun sekali seluruh warga mengikuti upacara di Pura Segara.

Saat kegiatan upacara keagamaan, warga kolok dipercaya untuk melaksanakan tugas kebersihan di lokasi upacara atau di pura. Sebelum upacara dimulai, warga kolok bertugas untuk membersihkan lokasi upacara. Demikian pula setelah upacara keagamaan selesai, warga kolok kembali bertugas untuk membersihkan lokasi tersebut. Mereka juga ditugaskan untuk membuat rajon, yaitu tempat untuk mencampur dan menyajikan lawar. Pada saat memasak untuk keperluan upacara, apabila aliran air terputus, dua-tiga orang kolok akan ditugaskan untuk mencari dan mengangkut air, sementara para kolok yang lain tetap membantu proses memasak.

Selain itu, apabila ada kematian, warga kolok sejak dahulu turun-temurun bertugas untuk menyiapkan lubang kuburan dan juga membersihkan areal 
kuburan tempat upacara akan dilaksanakan. Demikian pula setelah upacara selesai, kembali warga kolok yang membersihkan lokasi.(Wawancara tanggal 1 November 2015).

Berdasarkan penjelasan ini, dapat ditemukan pula bahwa keaktifan warga kolok di Desa Bengkala juga tidak terlepas dari peran dan kesediaan warga desa yang normal untuk menerima, membantu bahkan melibatkan mereka dalam berbagai kegiatan keagamaan walaupun warga kolok menempati posisi sebagai tenaga pendukung, tidak ada yang berperan sebagai pimpinan dalam upacara keagamaan.

\section{Tuhan, Yang kepadaNya Disampaikan Permohonan}

Warga kolok juga memahami bahwa kepada Tuhan manusia menyampaikan permohonan dan harapannya. Tuhan dipahami sebagai pribadi yang memiliki kuasa dan kekuatan yang lebih besar daripadanya. Berikut ini teks rekaman oleh Resmini (53th, buruh, tidak bersekolah, status: kawin).

Resmini: Menjelang Galungan ini, saya ingin membeli pisang. Bagaimana ya? Seandainya kita tidak membeli pisang, rasanya malu. Padahal saya sudah minta uang seratus ribu, dua ratus ribu untuk upacara. "Ayo, antar saya membeli pisang. Jika kamu bisa mengantar saya, itu bagus. Ayo, beli bahan-bahan maturan. Sekarang keadaannya hujan-hujan, tidak cocok nyacal (membuat jajan cacalan (semacam rangginang) karena baunya tidak enak, lembap. Sekarang nyacal (buat jajan cacalan) sedikit saja ya. Kalau dulu pisang banyak kan bagus? Saya selalu berdoa mohon agar kamu berhenti minum-minum agar tidak mabuk, jelek tahu? Saya juga mendoakan agar kamu rajin bekerja, agar kamu bisa mendapat banyak hasil sehingga bisa memberi saya uang.

Leluhur (dengan isyarat nama bapaknya yang sudah meninggal) melihat di saat kita bersembahyang saat Galungan. Berdoalah kamu. Belum lagi lima belas hari ke depan akan ada odalan, harus berpikir kita, tolong jangan kamu minum kesanakemari dulu. Saya sekarang tidak bekerja. Biasanya saya bekerja sebagai buruh angkut kelapa. Terima saja bahwa kamu harus memberi saya uang karena saya tidak bekerja lagi. Kamu tidak boleh marah. Bersyukurlah kepada Tuhan, itu lebih baik. Doakan anak kita sekolah di tempat yang jauh bolak-balik dengan baik. Warniapin sekolahnya dibantu oleh seorang (bermata sipit). Ada telepon yang memberitahu dia bahwa Warniapin tidak masuk sekolah dan mengingatkan kita agar mengantarnya kembali ke sekolah. Saya berjanji setelah Galungan akan mengantarnya ke sekolah. (Rekaman tanggal 9 Februari 2016).

Berdasarkan rekaman tersebut, diketahui bahwa kepada Tuhan, kolok Resmini menyampaikan permohonan dan harapannya. Ia pun menyarankan kepada suaminya untuk berdoa menyampaikan permohonannya kepada Tuhan, yang juga dipahami sebagai Leluhur.

\section{Peran Laki-Laki dan Perempuan dalam Kegiatan Keagamaan}

Dari sudut pandang gender, baik warga kolok laki-laki maupun perempuan memiliki perannya masing-masing dalam kegiatan keagamaan. Apabila ada upacara di Pura di Desa, umumnya mereka bertugas membersihkan areal pura sebelum dan sesudah acara dimulai. Warga kolok juga membantu dalam menyiapkan berbagai hal yang diperlukan untuk upacara. Warga kolok adalah warga yang rajin dalam tugas 
pekerjaannya dan memiliki inisiatif, mereka juga membantu mengingatkan tentang hal-hal yang diperlukan dalam kegiatan keagamaan. Biasanya mereka mengingatkan berdasarkan pengalaman yang mereka peroleh dalam kegiatan sebelumnya.

Ada hal yang unik yang diperoleh dari wawancara dengan warga kolok yang sudah hidup menjanda atau menduda. Mereka umumnya memilih untuk melaksanakan kegiatan persembahyangan di rumah masing-masing, tidak lagi pergi ke Pura untuk bersembahyang bersama seluruh warga desa. Alasannya karena kurang bersemangat atau juga karena malu. Berikut ini penjelasan dari Sandi (75th, buruh, tidak bersekolah, status: duda) dan Ragi (85th, buruh, tidak bersekolah, status: janda).

Ragi: Saya tidak pernah sembahyang. Semenjak suami saya meninggal dan banyak warga kolok tua yang sudah meninggal, saya tidak sembahyang ke Pura lagi karena saya malu. Biarkan mereka semua berkumpul dan bersembahyang. Saya hanya bersembahyang di rumah saja, saya bersembahyang di balePiyasan. Biasanya saya mandi, berhias, mesenteng (berpakaian adat), lalu bersembahyang di bale tempat sembahyang yang letaknya bersebelahan dengan kamar tidur saya. Bale tempat sembahyang itu dihias dengan langse (seperti kelambu) yang dulu saya beli. Dulu saya suka mengenakan kain yang berwarna cerah dan berkilau. Ibu saya yang membelikan kain itu untuk saya. (Wawancara tanggal 9 Februari 2016) Sandi: Semenjak isteri saya meninggal, saya merasa kurang semangat untuk bersembahyang. Dulu ketika isteri saya masih hidup, kami selalu bersembahyang bersama-sama. Sekarang isteri saya sudah meninggal, saya diam saja, tidak sembahyang lagi. Saya tetap sehat dengan bekerja menyabit rumput dan berladang, yang penting berkeringat saya merasa selalu sehat. Tetapi saya tetap menghaturkan kopi setiap pagi di Pelinggih Penunggun Karang dan di pelangkiran yang ada di kamar tidur dan di dapur sebelum saya minum kopi. Saya mengetahui tentang Tuhan. Tuhan itu selalu merasa kasihan kepada orang-orang. (Wawancara tanggal 9 Februari 2016).

Berdasarkan penjelasan dari kedua kolok ini, diketahui bahwa mereka tidak lagi giat untuk terlibat dalam kegiatan keagamaan secara bersama-sama. Meskipun demikian, mereka tetap rajin bersembahyang di rumah mereka sendiri. Dari hasil wawancara dengan kolok Sandi, bahkan jelas disebutkan bahwa Sandi mengetahui tentang Tuhan, yang menurutnya Tuhan itu selalu kasihan kepada orang-orang.

\section{Menyambut Tuhan dalam Hari Raya}

Seperti masyarakat desa Bengkala pada umumnya, warga kolok yang adalah pemeluk agama Hindu-Bali, merayakan Galungan dan Kuningan. Dalam rangka menyambut perayaan ini, mereka juga mengetahui dan berperan aktif dalam kegiatan perayaan tersebut. Berikut ini hasil rekaman wawancara dengan Sudarma (38th, buruh, tidak bersekolah, status: kawin) dan Pindu (46th, IRT, tidak bersekolah, status: kawin):

Sudarma: Besok akan Galungan, kebetulan hari ini ada orang meninggal. Kami kelompok penggali kubur harus menguburkannya dengan cara mekingsan di Pertiwi, di mana jenazah dikuburkan dengan permukaan tanah yang rata. Tujuannya agar seluruh warga desa tidak mengalami sandung atau sebel yakni keadaan tidak layak untuk bersembahyang; sehingga seluruh warga desa bisa merayakan Galungan. Pada tanah kuburan di bagian kepala jenazah, ditanam 
bambu untuk memasukkan semua sesaji dan tirta (air suci) yang akan dilaksanakan pada saat upacara penguburan, yaitu di hari ketiga sejak dari hari ini, atau setelah upacara perayaan Galungan selesai. Tiga hari kemudian barulah dilaksanakan upacara penguburan sebagaimana mestinya; setelah selesai bambu itu dicabut dan tanah kuburan dibentuk agak menggunung seperti layaknya bentuk kuburan. Hari keempat, seluruh warga desa dalam keadaan sandung atau sebel, di mana selama tiga hari mereka tidak boleh bersembahyang dan pergi ke Pura atau tempat suci agama Hindu. Setelah tiga hari barulah mereka kembali bersembahyang seperti biasa.

Besok (Galungan), pagi jam sembilan, saya pergi sembahyang ke Pura. Laki-laki maupun perempuan sama harus bersembahyang. Hari ini, nanti sore sekitar jam enam, saya membuat penjor di depan bersama semua laki-laki. Di setiap pemesuan (pintu keluar gang) ada satu penjor yang dibuat bersama-sama. Saya memperhatikan saat pembuatan penjor tersebut, bagian mana yang perlu dibantu, saya ikut bekerja di sana. Yang ikut membuat penjor hanya laki-laki yang masih muda, yang tua-tua tidak perlu ikut membuat penjor, mereka istirahat di rumah saja.

Pada hari Kuningan, tidak membuat lawar. Tidak membuat banten besar, hanya maturan (bersembahyang) di Pura di tempat penyimpanan air PAM. Di sini (Bengkala) berbeda dengan di tempat dingin (dataran tinggi) ataupun di Kota Singaraja, sebab mereka juga membuat lawar pada hari Kuningan. (Wawancara tanggal 9 Februari 2016)

Pindu: Saat perayaan Galungan (Penampahan), pagi hari ketika para laki-laki menyembelih dan membersihkan daging babi, saya dan para perempuan menyiapkan bumbu dan membuat sate, siang harinya membuat lawar merah menggunakan darah babi. Kemudian siangnya, setelah mebanten, saya membuat urutan (sosis babi tradisional Bali). Kemudian lawar yang sudah dibuat diolang lagi menjadi tum (sejenis makanan yang dibungkusdaunpisang dan dikukus).Selesai memasak kami makan bersama-sama sekeluarga. Jam sebelas siang, mulai metanding. Keesokan harinya jam tujuh pagi, mulai bersembahyang untuk merayakan Galungan, termasuk sembahyang di Sanggah Kumpi, Hyang Kompyang di Dadia (pura leluhur), dan di Pura Penunggun Karang. Pada hari Kuningan, di Bengkala perayaannya tidak semeriah Galungan, hanya sedikit membuat banten dan tidak membuat lawar ataupun masakan lainnya. (Wawancara tanggal 9 Februari 2016).

Berdasarkan hasil wawancara ini, diketahui bahwa dalam melaksanakan perayaan yang diambil sebagai contoh: Galungan dan Kuningan, laki-laki dan perempuan memiliki tugasnya masing-masing. Untuk kegiatan yang banyak menggunakan banyak tenaga fisik, generasi tua tidak dilibatkan. Untuk menyambut Tuhan dalam pelaksanaan Hari Raya seperti Galungan dan Kuningan dan berbagai hari-hari suci lainnya, sesuai keyakinan Hindu-Bali, tidak boleh dalam keadaan sandung atau sebel, yakni keadaan yang menyebabkan tidak layaknya orang melaksanakan peribadatan, keadaan yang dimaksud di antaranya: dalam kedukaan atau kesedihan, wanita yang sedang haid atau baru melahirkan, sakit kelainan, keguguran kandungan, lahir dari pasangan yang tidak diupacarai, dll. sesuai ketentuan tentang keadaan Cuntaka (sumber: http://inputbali.com/budaya-bali/berbagai-penyebab- 
cuntaka-dalam-hindu diakses 8 Januari 2019). Intinya, menyambut Tuhan harus dalam keadaan yang bersih dan layak.

Apabila diperhatikan, peran perempuan dalam kegiatan upacara terkesan lebih banyak, mereka yang menyiapkan berbagai sesaji yang dipersembahkan pada hari raya dan mereka juga yang berkeliling ke Pura-pura di wilayah desa untuk mempersembahkan sesaji tersebut. Berikut ini rekaman wawancara dengan Ngarda (52th, petani, tidak sekolah, status: kawin).

Ngarda: Setiap hari hanya isteri saya yang mebanten (bersembahyang), saya tidak ikut sembahyang. Di saat rerahinan hanya isteri saya yang mebanten sementara saya pergi menyabit rumput. Saat Galungan, apabila sudah selesai ngelawar, saya melihat perempuan sedang metanding (mempersiapkan sesaji/banten). Lalu isteri saya mengajak untuk pergi maturan (mempersembahkan sesaji ke Pura), "ayo kita pergi maturan!'kata isteri saya. Lalu saya mengantarnya ke Pura untuk bersembahyang dengan sepeda motor, setibanya di Pura, saya tinggal untuk melanjutkan menyabit rumput. Hal ini disebabkan peliharaan saya yang cukup banyak, ada empat ekor. Oleh karenanya cukup saya mengantar saja sampai di Pura, lalu isteri saya yang melanjutkan bersembahyang. Meskipun demikian, saya sudah berjanji dengan isteri saya kapan harus menjemputnya sehingga setelah selesai bersembahyang saya sudah siap untuk menjeputnya pulang. (Wawancara tanggal 16 Februari 2016)

\section{Perasaan Bahagia 'bertemu' dengan Tuhan}

Kegiatan keagamaan atau pengalaman bersembahyang ternyata dapat memberikan rasa bahagia kepada warga kolok, sebagaimana yang dirasakan oleh seluruh warga desa pada umumya. Berikut ini rekaman wawancara dengan Cening Sukesti (40th, buruh, tidak bersekolah, status: kawin).

Sukesti: Saat odalan di Pura Segara, semua kolok maupun yang normal berkumpul jam tujuh malam untuk berangkat bersama-sama dengan sepeda motor ke pantai. setelah bersembhayang di sana, jam sebelas malam kembali ke rumah masing-masing. Setiap odalan di Pura Segara kami tetap bersembahyang ke sana. Saya ikut naik perahu jukung ke tengah laut. Untuk perjalanan dengan jukung, jarak biasa membayar dua ribu rupiah sementara jarak yang lebih jauh ke tengah laut membayar lima ribu rupiah. Setiap kali ada persembahyangan saya merasa sangat gembira, semua kolok pun merasa senang. (Wawancara tanggal 31 Desember 2015)

Berdasarkan teks di atas diketahui bahwa kegiatan keagamaan juga merupakan sebuah rekreasi yang dapat melegakan perasaan mereka. Seperti yang dijelaskan oleh Sukesti, bahwa dirinya dan juga seluruh warga kolok merasa sangat gembira setiap kali mengikuti persembahyangan.

\section{Tuhan, Yang kepadaNya disampaikan Ucapan Syukur}

Wargakolok memahami bahwa sebagai manusia harus mengucap syukur kepada Tuhan, yang telah memberikan rezeki termasuk makanan dan minuman setiap hari. Kebanyakan dari mereka mengungkapkan rasa syukur dengan cara yang sederhana menurut tata cara Hindu-Bali yaitu dengan maturan jotan,yakni mempersembahkan sebagian kecil dari makanan ataupun minuman yang mereka buat 
atau masak. Berikut wawancara dengan Juliarta (31th, buruh, tidak bersekolah, status: kawin).

Menjelang jam satu saya bangun dari tidur siang dan saya ingin minum kopi. Tetapi saya tidak mau minum kopi jika belum ada yang bersembahyang maturan banten jotan. Teman-teman saling menyilahkan untuk membuat kopi bersamasama dan minum kopi. Sudah boleh minum kopi. Para perempuan menawari untuk sama-sama membuat dan minum kopi. Setelah itu, jam setengah satu siang, kami mulai bersiap-siap untuk kembali bekerja, memakai baju, menggunakan helm/topi, setelah itu memakai sepatu kanan dan memakai sepatu kiri, mengambil peralatan dan bersama-sama kembali bekerja. (Wawancara tanggal 20 Februari 2016).

Teks ini merupakan sebuah testimoni dari Juliarta bahwa dirinya belum bisa makan atau minum apabila belum maturan banten jotan. Ia merasa harus berdoa mengucap syukur kepada Tuhan dahulu sebelum menikmati makanan dan minuman.

\section{Simpulan}

Berdasarkan uraian pada pembahasan, dapat disimpulkan bahwa warga kolok Desa Bengkala memahami konsep Tuhan sebagai sesuatu yang diyakini keberadaannya dan kekuasaannya melebihi manusia, oleh karena itu, warga kolok Desa Bengkala melaksanakan kehidupan beribadah sebagai sesuatu yang menjadi bagian dari kehidupan mereka sehari-hari, yang sesungguhnya sejalan dengan konsep kehidupan beragama di Bali yang dijiwai oleh nilai-nilai Tri Hita Karana (Tiga Hal Penyebab Kebahagiaan) yang mengajarkan keharmonisan hubungan manusia dengan Tuhan, sesama dan lingkungan alam secara utuh. Warga kolok Desa Bengkala juga memiliki pengalaman relijius dengan merasakan bahwa Tuhan mengasihi mereka, serta mengungkapkan rasa terima kasih kepada Tuhan melalui kegiatan keagamaan.

\section{Rujukan}

Agastia, IB. Ed. 2006. Menemui Diri Sendiri. Percikan Pemikiran Prof. Dr. Ida Bagus Mantra. Denpasar: Yayasan Dharma Sastra.

Bogdan, R. C., \& Biklen, S. K. 1992. Qualitative research for education: An introduction to theory and methods. Boston: Allyn \& Bacon.

Cresswell, J. W., 2014. Research Design: Quantitative-Qualitative-MixedMethods-Approaches. Thousand Oaks, CA: Sage.

Hammersley, M. dan Atkinson, P. 1995. Ethnography. Principles in Practice. Edisi 2. London: Routledge.

Ibrahim, A. S. Ed. 2009. Metode Analisis Wacana. Yogyakarta: Pustaka Pelajar

Liang, et. al., 1998. Genetic mapping refines DFNB3 to 17p11.2, suggests multiple alleles of DFNB3, and supports homology to the mouse model shaker-2. Journal of Medical Genetics. v.62(4); 1998 Apr. 904-915.

Maisel, R. dan Persell, C. H. 1996. How Sampling Works. Thousand Oaks, CA: Pine Forge.

Miles, M. B., \& Huberman, A. M. (1994). Qualitative data analysis: A sourcebook of new methods. Thousand Oaks, CA: Sage.

Smith, Titus, Nolan. 1984. Persoalan-Persoalan Filsafat. Jakarta: Bulan Bintang.

Winata, S. dkk. 1995. "Congenital non-syndromal autosomal recessive deafness in Bengkala, an isolated Balinese village" dalam The American Journal of Genetics. h. 336 - 343 